\title{
Outlet obstructed constipation and fecal incontinence: is rehabilitation treatment the way? Myth or reality
}

\author{
Luigi BRUSCIANO ${ }^{1}$, Claudio GAMBARDELLA ${ }^{1,2}$, Gianmattia DEL GENI0 ${ }^{1}$, Salvatore TOLONE${ }^{1}$, \\ Francesco Saverio LUCIDO ${ }^{1}$, Gianmattia TERRACCIANO ${ }^{1}$, Giorgia GUALTIERI ${ }^{1}$ and Ludovico DOCIMO${ }^{1}$
}

ABSTRACT - Pelvic floor rehabilitation aims to address perineal functional and anatomic alterations as well as thoraco-abdominal mechanic dysfunctions leading to procto-urologic diseases like constipation, fecal and urinary incontinence, and pelvic pain. They require a multidimensional approach, with a significant impact on patients quality of life. An exhaustive clinical and instrumental protocol to assess defecation disorders should include clinical and instrumental evaluation as well as several clinical/physiatric parameters. All these parameters must be considered in order to recognize and define any potential factor playing a role in the functional aspects of incontinence, constipation and pelvic pain. After such evaluation, having precisely identified any thoraco-abdomino-perineal anatomic and functional alterations, a pelvi-perineal rehabilitation program can be carried out to correct the abovementioned alterations and to obtain clinical improvement. The success of the rehabilitative process is linked to several factors such as a careful evaluation of the patient, aimed to select the most appropriate and specific targeted rehabilitative therapy, the therapist's scrupulous hard work, especially as regards the patient's emotional and psychic state, and finally the patient's compliance in undertaking the therapy itself, especially at home. These factors may deeply influence the overall outcomes of the rehabilitative therapies, ranging from "real" success to illusion "myth".

HEADINGS - Constipation. Intestinal obstruction. Fecal incontinence. Pelvic floor disorders, rehabilitation. Physical therapy modalities.

Keypoints

- Patients affected by defecatory disorders necessitate by a novel multidimensional approach.

- In addition to the well knowledge pelvic floor evaluation (clinical scores and instrumental features) we propose a clinical-physiatric assessment.

- The clinical-physiatric evaluation add a functional evaluation of thorax, abdomen and perineum all considered as three different parts of the same whole.

\section{INTRODUCTION}

Pelvic floor dysfunction is a widespread condition caused by injury, alteration and degeneration of pelvic floor support tissues and, as any functional disorder, it is related to either anatomical or functional factors. It is a complex nosographic entity whose correct identification requires a multidimensional approach, with a significant impact on patients daily activity and quality of life. Currently, in order to reduce the possibility of postoperative inadequate results or complications, several surgeons tend to address these patients to pelvic floor rehabilitation, without a careful clinical and instrumental evaluation. Achieving good long-term outcome is an ambitious project, that needs to be well investigated and standardized. It is in fact of paramount importance to accomplish a detailed evaluation of physiatric and instrumental features in order to identify patient's suitableness for pelvi-perineal rehabilitation treatment. The paper aims to exhaustively analyze the functional aspects involved in those physio-pathologic mechanisms that lead to pelvic disorders (e.g. constipation, fecal and urinary incontinence), and to describe the currently available re-educational and rehabilitative tools based on our referral center experience.

\section{Bowel ano-rectal disorders}

Constipation and fecal incontinence are very common in developed countries with $12 \%$ to $19 \%$ of adults being affected. They are the most common defecatory disorders, recognizing functional and anatomical basis. Constipation consists in the difficult defecation of hard stools, that leads to a prolonged single evacuation (over 15 minutes), increased straining and tenesmus. It is either related to an inadequate introduction of dietary elements or to colorectal anatomical or functional disorders ${ }^{(1)}$. Constipation can in fact be simply related to a bad bowel management as happening for an apparently broken-down car suspected of engine failure, resulting in just lack of fuel instead. Thus, colon needs its fuel that is composed of three elements that are water, fibers and probiotics. An adequate diagnostic process about constipation shouldn't in fact lack of information about the stool feces ${ }^{(2)}$. On the other hand,

Declared conflict of interest of all authors: none

Disclosure of funding: no funding received

${ }^{1}$ University of Campania "Luigi Vanvitelli", Division of General, Mininvasive and Bariatric Surgery, Naples, Italy. ${ }^{2}$ University of Campania "Luigi Vanvitelli", School of Medicine, Department of Cardiothoracic Sciences, Naples, Italy.

Corresponding author: Claudio Gambardella, MD, PhD. E-Mail: claudiog86@hotmail.it 
constipation may have functional causes such as compromised coordination between rectum and anus and an altered synergy of thoraco-abdominal muscles (both improvable with rehabilitation treatment $)^{(3-7)}$. Functional constipation can be defined as "colic" when associated to a slow colonic transit and "rectal", when associated to pelviperineal dyssynergia (outlet dysfunction type). Obviously, rectal constipation can be determined by anatomical defects of the rectum itself, such as rectocele and recto-rectal intussusception. Such anatomical alterations can only be treated by a surgical approach. Pelviperineal rehabilitation is nowadays recognized as a proper treatment approach for constipation, associated with dietary and behavioral modifications when failure of conventional therapies may occur, when the diagnosis of anorectal functional constipation is correct, and the coordination disturbance is studied and clinically severe ${ }^{(8)}$. Fecal incontinence (patient's impossibility to hold feces or gas), is as well largely associated to functional alterations such as sphincteral muscular deficit, sensory deficit or muscular innervation deficit, all of these features can be amended by adequate pelvic floor rehabilitation. Pelvic floor rehabilitation has a sort of established indication in fecal incontinence, according to literature in fact, pelvic floor rehabilitation may only be certainly useful for active incontinence even though, in passive incontinence, rehabilitation may be used to obtain striated muscle strengthening and a better awareness of the pelvic floor for better symptom management ${ }^{(8)}$. In our referral centre, we've had discrete results both in active, passive and mixed incontinence when due to functional matters. Certainly, concomitant anatomical alterations like anal sphincteral damage or previous rectal surgery can make rehabilitation programs less effective and should be addressed to surgery.

\section{FUNCTIONAL ASSESSMENT}

\section{Clinical-physiatric evaluation}

In order to improve pelvic floor dynamics, proctologists should identify causes of pathologic evacuation. A physiological defecation act is not only controlled by rectal and anal synergy, but also by muscular dynamics between thorax, abdomen and perineum, in addition to a correct posture. The ability in realizing correct synergic movements is in fact not always properly developed in general population ${ }^{(9-12)}$. Literature data is still very poor on this topic: there's lack of a proper set of values that might help objectifying when to indicate pelvic floor rehabilitation and how to quantify results. Thus, in consideration of the difficulty of obtaining shared normal values, every centre still uses its own values and clinical evaluations to deal with this kind of approach. Evaluation of patients reporting pelvic floor dysfunction is now committed to different clinical or instrumental scores, only graduating the presence and severity of the disease as Wexner and Altomare scores ${ }^{(13-16)}$.

We believe, instead, that a proper diagnostic process should combine, in addition to clinical and instrumental values, several clinical/physiatric parameters such as puborectalis muscle function, perineal defense reflex, agonist and antagonist muscle synergies, and last but not least, postural examination (lumbar lordosis) and respiratory function. We are aware that this kind of diagnostic approach is not standardized or objectionable yet, but our beliefs are strongly supported by our large clinical experience. In our protocol all these parameters must be considered in order to recognize and define any functional aspect of incontinence, constipation and pelvic pain ${ }^{(16,17)}$. We currently study all of these aspects as follows:
Puborectalis function can be evaluated with rectal exploration, but also with anorectal manometry, dynamic defecography and transanal ultrasonography. If the pubo-rectal muscle relaxes, the axis between the rectum and anal canal aligns, and the stool can transit. This explains the importance of pubo-rectal muscle evaluation to define whether relaxation is absent, incomplete or paradoxical.

The pubococcygeal test $(\mathrm{PC})$ is performed by inserting a finger, hooking the anal canal and vagina in order to evaluate muscle tonic and phasic contraction, muscular strength and symmetry of the left and right muscular branches.

Perineal defense reflex is considered as an expression of correct abdomino-perineal dynamics ${ }^{(18-21)}$. It evaluates the action of the pelvic floor during forced expiration, when the diaphragm generates a high intra-abdominal pressure. The patient is asked to cough, to allow the proctologist to register the contraction of perianal muscles, that cause a physiological increase (positive reflex) or a pathological drop (negative reflex). Pathological drop is associated with urinary, gas incontinence and soiling ${ }^{(18-20)}$. It is mandatory to also evaluate muscular synergies by anal contraction with the patient in Sims position ${ }^{(22,23)}$. The recruitment of agonist muscles, such as the gluteus and abductor groups, during anal sphincter contraction can be caused by the patient's incapacity to selectively recruit the correct muscles for the requested order ${ }^{(24)}$. Vice versa, the identification of antagonist muscles, (abdominals) during the anal sphincter contraction phase represents a conflict between the abdominal and perineal muscles. Posture may also affect pelvic floor dissynergies ${ }^{(25,26)}$. Its examination should be performed by a plumb line, that helps evaluating lumbar lordosis. It impacts on orientation of the sacral promontory, anorectal angle and puborectal tone. All these important functional and anatomical parameters are part of the clinical physiatric Brusciano Rehabilitation Score System ${ }^{(17)}$.

\section{Respiratory dynamic correlation}

A physiologic defecation is not only related to a correct action of the pelvic floor, but also requires a synergic function of thoracic and abdominal muscles ${ }^{(5,6)}$. The rectal filling sensation works as trigger for the defecatory act, then a Valsalva maneuver is physiologically requested; thoracic diaphragm is pushed downward, abdominal muscles are contracted, and the pelvi-perineal floor descend determining a significant increase of the intra-rectal pressure with an effective straining on defecation. Although, if our target is to improve perineal function and ameliorate defecation, it is mandatory to also highlight the contribution of either diaphragm and abdominal muscles to the Valsalva maneuver ${ }^{(6,7)}$. As by now it is well known, this maneuver is mainly affected by the position of diaphragm during the maximal intraabdominal strength. Indeed, the pression generated inside the abdominal cavity is inversely proportional to the radius of the sphere (Laplace's law). Given the tension of the contracted anterior abdominal wall along with the proper alignment of the spinal column, the other element playing a substantial role in either reducing volume or increasing intraabdominal pressure, is contraction and descent of the diaphragmatic muscles. This movement may appear simple and ordinary, but it is largely affected instead by the type and method of respiratory mechanics. "Costal" breathing achieves a minimal upper/lower movement, while a correct "diaphragmatic" breath allows a wider excursion. In patients with predominant costal breathing, an absent or ineffective diaphragmatic movement can be improved by simple exercises focused on respiratory coordination ${ }^{(5,6)}$. 


\section{Instrumental evaluation}

Instrumental indexes, especially manometric ones, are nowadays deeply known and fully used to indicate rehabilitation. What we aim to add, is that objective parameters alone do not complete the diagnostic process, if they are not properly inserted in the patient functional evaluation of thorax, abdomen and perineum; all considered as three different parts of the same whole. The clinical-physiatric evaluation we apply in our referral centre can in fact be considered a novel approach in the assessment of the pelvic floor dysfunctional patient. Nevertheless, in order to achieve a full evaluation of the functional or anatomical alterations, instrumental findings are mandatory. The anorectal manometry evaluates the pressures and volumes of the rectum and anal canal, highlighting significant alterations in patients with constipation and incontinence. Incontinence is often characterized by lower basal pressures and lower pressure during voluntary contraction, as reflected by altered rectal sensitivity and recto-anal inhibitory reflex. Rectal compliance is reduced with increased spontaneous relaxations. In constipation, anal pressure profile can either be normal or hypertonic, but associated with altered recto-anal inhibitory reflex and reduced sensibility to defecate, only evocated by higher volumes. This is consistent with the principle that the association of adequate anal canal relaxation and lower residual pressure determines a sufficient gradient for defecation ${ }^{(27-30)}$. Defecography shows better than any other investigation the rectal morphology by showing the relationship between the anal canal and pubococcygeal level (i.e. rectocele or recto-rectal intussusceptions), and investigating them during defecatory function (e.g. rest, straining and defecation act). An incomplete or absent relaxation of the puborectal muscle, with the subsequent incomplete or absent extension of anorectal angle, is a typical finding of constipation. In incontinent patients the most common feature is the loss of barium particles during coughing. Endoanal and perineal ultrasound is mandatory to exclude presence of sphincteral defects (i.e. lesions, inhomogeneity, outright interruptions) that can cause idiopathic or traumatic incontinence, and moreover it is able to asses puborectal muscle function ${ }^{(31,32)}$.

\section{Rehabilitation treatment}

Rehabilitation should start with a patient's re-educational phase. This process aims to improve an altered bodily function; it is not merely cognitive, while it prepares the patient toward an active, rather than a passive, role with a deep participation during the healing process. Even according to Bocchini et al., this phase is as important as the others as it has the aim of improving anorectal physiological functions corticalization through a progressively better awareness of such body areas ${ }^{(2)}$.

The second phase aims to heal functional alterations by different techniques (biofeedback, electrostimulation, physiokinesitherapy and volumetric rehabilitation) in order to address every single alteration. These techniques should be considered as systematic part of a whole process, not single separable steps, and therefore an undetermined and unweighted medical indication of "just do a biofeedback!" should be avoided ${ }^{(33)}$.

Correct rehabilitation is composed of three main steps:

1. Re-educational feature: patients are taught anatomical and physiological functions of the body area which will be treated, in order to best interact during rehabilitation; they have to gain proper acknowledge about anatomical and functional aspects of their perineum in order to correctly govern it.
2. Practical exercise to obtain functional and postural recovery. In case of electrostimulation, anal or vaginal probes perform electrical stimulation of nerves and muscles, allowing an appropriate and precise visualization of patient's muscular activity. Given probes are connected to a monitor, patients can observe their muscular activity simultaneously (biofeedback), learning coordination while eliminating their mistakes. Its reliability to increase the patient's awareness during both contraction and relaxation training is now well assessed ${ }^{(34)}$. The volumetric rehabilitation method artificially simulates urge or delayed need to defecate, trough graduated enema, modulating rectal sensibility threshold with the aim of normalizing their physiological function. In addition, with physiokinesitherapy the rehabilitator basically uses their hands to rebalance bodily functions, after a careful evaluation of the patient's osteo-muscular state. It is in fact an active technique with the aim of allowing the patient to learn or re-learn correct muscle and functional behaviors forgotten or never learnt, in order to lead to a normal defecation. Assisted and against-resistance exercises are performed to adequately stimulate the perineal muscles and properly involve synergic muscles and those of the anal sphincter. In this phase, the patient is also trained throughout easy exercises on how to gain the correct respiratory dynamics because of the contribution of either diaphragm and abdominal muscles to the Valsalva maneuver, as explained before.

3. Home self-executing of gained movements and consciousness in everyday life, as natural patient's behavior.

In order to reach a successful rehabilitation and maintain a normal bodily function, patients should keep what they have learned about bodily anatomy and rehabilitation exercises, with a complete summarize and correct coordination of the techniques during everyday life.

Rehabilitation therefore begins in the rehabilitative ambulatory but continues at home and is constantly carried out until the patient is healed and thereafter (like in every workout training). Moreover, advantages of rehabilitation program can only be effective if patient actively participates not only physically, but also mentally ${ }^{(35)}$.

\section{CONCLUSION}

The overall path of rehabilitation consists in strengthening and harmonizing the different muscles of the pelvic floor, not only with their self but also with the rest of the body. The acts of retention or expulsion (urinating and/or defecating) does not solely depend upon the pelvic floor but it consists in a complex result of simultaneous coordination with the pelvic floor itself, with the chest and abdomen. For an exhaustive assessment of a dysfunctional patient, clinical status, instrumental features, and physiatric patterns, should be evaluated in order to define which patients will best benefit from a pelviperineal rehabilitation program ${ }^{(17)}$. It should be modulated on patient's emotional and psychic state, and its ability to collaborate in undertaking a proper therapy when back home.

Thus, the mere correction of single alterations found during the physio-clinical study might not be effective in healing every defecatory or urinary disorder and their related symptoms, but surely improves the clinical conditions with positive impact on Wexner and Pescatori score. On the other hand, the improvements of Brusciano Score parameters could not reflect in a clinically relevant improvement of symptoms. Overall outcomes of the 
rehabilitative process are linked to several different factors and may deeply change results, ranging from "real" success to illusion "myth". It is clear why surgery should be considered as a standard of care only in case of clinical symptoms related to not modifiable anatomical defects.

This paper aims to spread the concept that pelvi-perineal rehabilitation should be adopted as part of a multi-modal therapy, only after having detected the proper indications, while if it is only suggested in case of failure of previous other treatments, as it usually currently happens, it may achieve poor results and thus remain a false "myth".

\section{Authors' contribution}

Brusciano L and Gambardella C contributed to conception, design and drafting of the article; del Genio G, Tolone S, Terracciano $G$, Gualtieri $G$ and Lucido FS contributed to acquisition and interpretation of data; Docimo L revised it critically and gave final approval of the version to be published.

\section{Orcid}

Luigi Brusciano: 0000-0003-4112-1282.

Claudio Gambardella: 0000-0003-2277-2960.

Gianmattia del Genio: 0000-0001-5603-8970.

Salvatore Tolone: 0000-0002-1653-9903.

Francesco Saverio Lucido: 0000-0002-8778-4690.

Gianmattia Terracciano: 0000-0002-3759-1583.

Giorgia Gualtieri: 0000-0002-9591-1856.

Ludovico Docimo: 0000-0001-5587-9452.

Brusciano L, Gambardella C, del Genio G, Tolone S, Lucido FS, Terracciano G, Gualtieri G, Docimo L. Constipação com obstrução à saída e incontinência fecal: o tratamento de reabilitação é o caminho? Mito ou realidade. Arq Gastroenterol. 2020;57(2):198-202.

RESUMO - A reabilitação do assoalho pélvico visa abordar alterações funcionais e anatômicas perineais, bem como disfunções mecânicas torácicas-abdominais que levam a doenças procto-urológicas como prisão de ventre, incontinência fecal e urinária e dor pélvica. Requerem uma abordagem multidimensional, com impacto significativo na qualidade de vida dos pacientes. Um protocolo clínico e instrumental exaustivo para avaliar os transtornos de defecação deve incluir avaliação clínica e instrumental, bem como diversos parâmetros clínicos/fisiátricos. Todos esses parâmetros devem ser considerados para reconhecer e definir qualquer fator potencial desempenhando um papel nos aspectos funcionais da incontinência, prisão de ventre e dor pélvica. Após tal avaliação, tendo identificado com precisão quaisquer alterações anatômicas e funcionais tóraco-abdomino-perineais, um programa de reabilitação pelvi-perineal pode ser realizado para corrigir as alterações acima mencionadas e obter melhora clínica. O sucesso do processo de reabilitação está ligado a diversos fatores, como uma avaliação cuidadosa do paciente, visando selecionar a terapia de reabilitação direcionada mais adequada e específica, além do trabalho árduo e escrupuloso do terapeuta, especialmente no que diz respeito ao estado emocional e psíquico do paciente e, finalmente, a conformidade do paciente em realizar a terapia em si, especialmente em casa. Esses fatores podem influenciar profundamente os resultados globais das terapias de reabilitação, que vão desde o sucesso "real" até o "mito" ilusório.

DESCRITORES - Constipação intestinal. Obstrução intestinal. Incontinência fecal. Distúrbios do assoalho pélvico, reabilitação. Modalidades de fisioterapia.

\section{REFERENCES}

1. Brusciano L, Limongelli P, del Genio G, Rossetti G, Sansone S, Healey A, et al. Clinical and instrumental parameters in patients with constipation and incontinence: their potential implications in the functional aspects of these disorders. Int J Colorectal Dis. 2009;24:961-7.

2. Lewis SJ, Heaton KW. Stool form scale as a useful guide to intestinal transit time. Scand J Gastroenterol. 1997;32:920-4.

3. Higgins PD, Johanson JF. Epidemiology of constipation in North America: a systematic review. Am J Gastroenterol. 2004;99:750-9.

4. Pucciani F, Rottoli ML, Bologna A, Cianchi F, Forconi S, Cutellè M, Cortesini C. Pelvic floor dyssynergia and bimodal rehabilitation: results of combined pelviperineal kinesitherapy and biofeedback training. Int J ColorectDis. 1998;13:124-30.

5. Pucciani F, Iozzi L, Masi A, Cianchi F, Cortesini C. Multimodal rehabilitation for faecal incontinence: experience of an Italian centre devoted to faecal disorder rehabilitation. Tech Coloproctol. 2003;7:139-47.

6. Chiarioni G, Whitehead WE, Pezza V, Morelli A, Bassotti G. Biofeedback is superior to laxatives for normal transit constipation due to pelvic floor dyssynergia. Gastroenterology. 2006;130:657-64.

7. Battaglia E, Serra AM, Buonafede G, Dughera L, Chistolini F, Morelli A, et al. Long-term study on the effects of visual biofeedback and muscle training as a therapeutic modality in pelvic floor dyssynergia and slow transit constipation. Dis Colon Rectum. 2004:47:90-5.

8. Bocchini R, Chiarioni G, Corazziari E, Pucciani F, Torresan F, Alduini P, et al. Pelvic floor rehabilitation for defecation disorders. Tech Coloproctol. 2019;23: 101-15.

9. Pages IH, Jahr S, Schaufele MK, Conradi E. Comparative analysis of biofeedback and physical therapy for treatment of urinary stress incontinence in women. Am J Phys Rehabil. 2001;80:494-502.
10. Dumoulin C, Seaborne DE, Quirion-DeGirardi C, Sullivan SJ. Pelvic-floor rehabilitation, part 2: pelvic-floor reeducation with interferential currents and exercise in the treatment of genuine stress incontinence in postpartum women-a cohort study. Phys Ther. 1995;75:1075-81.

11. Bourcier AP. Physical therapy for female pelvic floor disorders. Curr Opin Obstet Gynecol. 1994;6:331-5.

12. Galeri S, Sottini C. Physiotherapy of pelvic floor for incontinence. ArchItal Urol Androl. 2001;73:143-6.

13. Altomare DF, Di LM, Giuratrabocchetta S, Giannini I, Falagario M, Zbar AP, Rockwood T. The Three Axial Perineal Evaluation (TAPE) score: a new scoring system for comprehensive evaluation of pelvic floor function. Colorectal Dis. 2014;16:45968.

14. Altomare DF, Di LM, Andriola V, Giuratrabocchetta S, Giannini I, Ferrara C. TriAxial perineal evaluation score: the male version. Colorectal Dis. 2015; 17:544-5.

15. Altomare DF, Spazzafumo L, Rinaldi M, Dodi G, Ghiselli R, Piloni V. Set-up and statistical validation of a new scoring system for obstructed defaecation syndrome. Colorectal Dis. 2008;10:84-8.

16. Jorge JM, Wexner SD. Etiology and management of fecal incontinence. Dis Colon Rectum. 1993;36:77-97.

17. Brusciano L, Limongelli P, Del Genio G, Di Stazio C, Rossetti G, Sansone S, et al. Short-term outcomes after rehabilitation treatment in patients selected by a novel rehabilitation score system (Brusciano score) with or without previous stapled transanal rectal resection (STARR) for rectal outlet obstruction. Int J Colorectal Dis. 2013;28:783-93.

18. Rocca Rossetti S. Functional anatomy of pelvic floor. Arch Ital Urol Androl. 2016;88:28-37. 
19. Di Benedetto P. La valutazione neuro-fisiatrica perineale. Riabilitazione uro-ginecologica. Edizioni Minerva Medica. 2004;99-103.

20. Brusciano L, Gambardella C, Tolone S, Del Genio G, Terracciano G, Gualtieri $\mathrm{G}$, et al. An imaginary cuboid: chest, abdomen, vertebral column and perineum, different parts of the same whole in the harmonic functioning of the pelvic floor. Tech Coloproctol. 2019;23:603-5. doi: 10.1007/s10151-019-01996-x.

21. Hay-Smith EJ, Dumoulin C. Pelvic floor muscle training versus no treatment, or inactive control treatments, for urinary incontinence in women. Cochrane Database Syst Rev. 2006;1:CD005654.

22. Araujo CC, Coelho SSA, Martinho N, Tanaka M, Jales RM, Juliato CRT. Clinical and ultrasonographic evaluation of the pelvic floor in primiparous women a cross-sectional study. Int Urogynecol J. 2018;29:1543-9.

23. Herbison P, Plevnik S, Mantle J. Weighted vaginal cones for urinary incontinence Cochrane Database Syst Rev, 2002.1:CD002114

24. Brusciano L, Limongelli P, del Genio G, Sansone S, Rossetti G, Maffettone V, et al. Useful parameters helping proctologists to identify patients with defaecatory disorders that may be treated with pelvic floor rehabilitation. Tech Coloproctol 2007; $11: 45-50$.

25. De Troyer A. Mechanical role of the abdominal muscles in relation to posture. Respir Physiol. 1983;53:341-53.

26. Kera T, Maruyama $H$. The effect of posture on respiratory activity of the abdominal muscles. J Physiol Anthropol Appl Human Sci. 2005;24:259-65.

27. Whitehead WE, Orr WE, Engel BT, Schuster MM. External anal sphincter response to rectal distension: learned response or reflex. Psychophysiology. 1982;19:57-62.
28. Caetano AC, Dias S, Santa-Cruz A, Rolanda C. Renzi score for obstructed defecation syndrome - validation of the portuguese version according to the cosmin checklist. Arq Gastroenterol. 2018;55:55-60.

29. Murad-Regadas SM, Regadas FS, Rodrigues LV, Fernandes GO, Buchen G, Kenmoti VT. Management of patients with rectocele, multiple pelvic floor dysfunctions and obstructed defecation syndrome. Arq Gastroenterol. 2012;49:135-42.

30. Teng M, Kervinio F, Moutounaïck M. Review of pelvic and perineal neuromuscular fatigue: Evaluation and impact on therapeutic strategies. Ann Phys Rehabil Med. 2018;61:345-51.

31. Brusciano L, Limongelli P, Pescatori M, Napolitano V, Gagliardi G, Maffettone $\mathrm{V}$, et al. Ultrasonographic patterns in patients with obstructed defaecation. Int J Colorectal Dis. 2007;22:969-97.

32. Kannan P, Winser S, Fung B, Cheing G. Effectiveness of Pelvic Floor Muscle Training Alone and in Combination with Biofeedback, Electrical Stimulation, or Both Compared to Control for Urinary Incontinence in Men Following Prostatectomy: Systematic Review and Meta-Analysis. Phys Ther. 2018;98: 932-45.

33. Gambardella C, Brusciano L, Del Genio G, Tolone S, Terracciano G, Gualtieri G Predictive parameters to identify incontinent patients amenable for rehabilitation treatment: the muscular synergies evaluation. Arq Gastroenterol. 2019;56:452-3.

34. Rao SS, Benninga MA, Bharucha AE, Chiarioni G, Di LC, Whitehead WE. ANMS-ESNM position paper and consensus guidelines on biofeedback therapy for anorectal disorders. Neurogastroenterol Motil. 2015;27:594-609.

35. Del Genio A, Brusciano L, Sansone S. Riabilitazione del Pavimento Pelvico: in colloquio con i pazienti. Naples: Idelson Gnocchi; 2009. 